\title{
Evaluation of Acid-treated Fish Sarcoplasmic Proteins on Physicochemical and Rheological Characteristics of Pork Myofibrillar Protein Gel Mediated by Microbial Transglutaminase
}

\author{
Bung-Orn Hemung ${ }^{1}$ and Koo Bok Chin* \\ Department of Animal Science and Functional Foods Research Institute, College of Agriculture and Life Science, \\ Chonnam National University, Gwangiu 500-757, Korea \\ ${ }^{1}$ Faculty of Applied Science and Engineering, Khon Kaen University, Nong Khai Campus, Thailand, 43000
}

\begin{abstract}
Fish sarcoplasmic protein (SP) is currently dumped as waste from surimi industry and its recovery by practical method for being the non-meat ingredient in meat industry would be a strategy to utilize effectively the fish resource. This study was aimed to apply $\mathrm{pH}$ treatment for fish SP recovery and evaluated its effect on pork myofibrillar protein (MP) gel. The $\mathrm{pH}$ values of fish SP were changed to 3 and 12, and neutralized to $\mathrm{pH} 7$ before lyophilizing the precipitated protein after centrifugation. Acid-treated fish SP (AFSP) showed about 4-fold higher recovery yield than that of alkaline-treated SP and water absorption capacity was also about 1.2-fold greater. Because of the high recovery yield and water absorption capacity, AFSP was selected to incorporate into MP with/without microbial transglutaminase (MTG). The effects of AFSP and MTG on the physicochemical and rheological characteristics of MP and MP gel were evaluated. MTG induced an increase shear stress of the MP mixture and increase the breaking force of MP gels. MP gel lightness was decreased by adding AFSP. MP gel with MTG showed higher cooking loss than that without MTG. A reduction of cooking loss was observed when the AFSP was added along with MTG, where the insoluble particles were found. Therefore, AFSP could be contributed as a water holding agent in meat protein gel.
\end{abstract}

Key words: sarcoplasmic proteins, microbial transglutaminase, water absorption capacity, pork myofibrillar protein, $\mathrm{pH}$ treatment

\section{Introduction}

Sarcoplasmic protein (SP) is a water-soluble protein located in the sarcoplasm of animal tissue. It is categorized into myogens, albumin, and glycolytic and proteolytic enzymes. Currently, fish SP is removed out by washing the fish mince with a huge volume of water to obtain the concentrated myofibrillar protein (surimi). This process is necessary since SP might cause the deterioration and defect to the surimi. However, fish SP may have important functions. In surimi processing, a high volume of water is used and discarded as waste. In seeking to recover and use the SP in the waste water, direct centrifugation of the wash water generated by a surimi factory was explored (Lin et al., 1995). Montero and Gomez-

*Corresponding author: Koo Bok Chin, Department of Animal Science, Chonnam National University, Gwangju 500-600, Korea. Tel: +82-62-530-2121, Fax: +82-62-530-2129 E-mail: kbchin@jnu.ac.kr
Guillen (1998) applied ultrafiltration to recover soluble proteins from krill. Lyophilization of whole SP solution to produce SP powder from the rockfish has been tried (Kim et al., 2005). However, such large-scale methods for the recovery of SP may not be practical and is limited by the high production cost.

The characteristics of SP can be altered by treatment with acid/alkaline solutions (Tadpitchayangkoon et al., 2010). Acid/alkaline induces partial denaturation of SP, which results in protein precipitation. Thus, acid or alkaline treatments may provide a practical way to recover SP from solution. Lyophilization of the precipitated protein may be a promising method to generate food protein ingredient from SP recovered from waste water.

SP powder can render water into a food matrix and water holding capacity (WHC) increases when SP is treated at acidic/alkaline conditions (Yongsawatdigul and Hemung, 2010). Thus, it is possible to introduce $\mathrm{pH}$-treated SP powder as a water binding agent in a protein gel. Unfortunately, application of recovered SP in surimi gel 
is still limited since it may affect the color, especially whiteness (Jafarpour and Gorczyca, 2009). Moreover, addition of lyophilized SP powder to protein gels diminishes gelling properties due to the remaining proteinase activity (Go and Hwang, 1995). In addition, the interactions between fish SP and MP increase the thermal stability of fish MP and retard gel formation (Hemung and Chin, 2013).

Application of pH-treated SP into pork protein gel is more likely, since more colorful products are acceptable. Understanding the effect of $\mathrm{pH}$-treated SP on pork MP during gelation would be the useful information to evaluate the possibility to apply SP into meat products, especially in the present of microbial transglutaminase (MTG).

MTG catalyses acyl transfer from glutamine-linked peptides/proteins to lysine-linked proteins, resulting in the cross-linking via isopeptide bonds of proteins (Ando et al., 1989). MTG has been broadly employed to improve textural properties of food protein gels (Ahmedna et al., 1999). Although MTG could be a useful ingredient, increased cooking loss was also observed (Hong and Chin, 2010). Addition of non-meat proteins has been applied to reduce cooking loss and improve the cooking yield of MTG-mediated protein gels (Perez-Alvarez et al., 1999). However, application of $\mathrm{pH}$-treated fish SP as the water binding agent in MTG-mediated protein gel from pork has not been investigated. Therefore, the aim of this study was to investigate the functional properties of $\mathrm{pH}-$ treated fish SP to select a superior water binding agent. Then, effects of fish pH-treated SP on the physicochemical and rheological characteristics of MTG-mediated MP gel from pork were evaluated.

\section{Materials and Methods}

\section{Fish and pork sample preparation}

Pork loin samples (four pieces) from porcine M. Longissimus dorsi (Crossbreed of Landrace $\times$ Yorkshire $\times$ Duroc) were prepared at $24 \mathrm{~h}$ post-mortem. The visible fat and connective tissue were trimmed out before cutting into a cubic shape prior to vacuum storage at $-70^{\circ} \mathrm{C}$ until utilized. Red sea bream (Pagrus major) samples were purchased from Gunnae-ri, Dolsan-eup, Yeosu-si, and Jeollanam-do, Korea. Fish samples $(30-35 \mathrm{~cm})$ were delivered to the Meat Science Laboratory, Chonnam National University, South Korea, in a foam box covered in an ice. The fish samples were eviscerated, filleted manually, cut into cubic shape and kept at $-70^{\circ} \mathrm{C}$ under vacuum until used. MTG ( $1 \%$ of pure MTG) was from Ajinomoto Ko- rea (Korea). Other chemicals were of analytical grade.

\section{Fish SP preparation}

After the frozen fish samples ( $200 \mathrm{~g}$ ) were thawed in a cold room overnight, they were homogenized with 3 volumes of de-ionized water (DI-water) for $2 \mathrm{~min}$. The homogenate was centrifuged for $15 \mathrm{~min}$ at $1,000 \mathrm{~g}$ and collected the supernatant for being the SP solution before dividing into 2 parts (Hemung and Chin, 2013). The first part was adjusted to $\mathrm{pH} 3$ using $3 \mathrm{~N}$ of $\mathrm{HCl}$ and the second part was adjusted to $\mathrm{pH} 12$ using $3 \mathrm{~N}$ of $\mathrm{NaOH}$. The $\mathrm{pH}$-treated mixture was kept at $4^{\circ} \mathrm{C}$ for $30 \mathrm{~min}$. Subsequently, the solutions were neutralized to $\mathrm{pH} 7$ with $3 \mathrm{~N}$ of $\mathrm{NaOH}$ or $\mathrm{HCl}$. The precipitate was collected by centrifugation at $1,000 \mathrm{~g}$ for $15 \mathrm{~min}$ and lyophilized to yield acid-treated or alkaline-treated SP using a model 5508 freeze dryer (MFCD, Ilshin, Korea). The recovery yield was also recorded to evaluate the effectiveness of recovering procedure.

\section{SP characterization}

\section{Water absorption capacity (WAC)}

WAC was measured according to the method described by Yongsawatdigul and Hemung (2010) with slight modifications. Dried sample (200 mg) was placed in the preweighed microcentrifuge tube before adding the DI water until sample was saturated (approximately $0.7 \mathrm{~mL}$ ). All samples were centrifuged at $2,000 \mathrm{~g}$ for $10 \mathrm{~min}$ before discarding the liquid. Then, the remaining pellet was weighted to calculate the amount of gained water by subtraction with original weight. WAC was calculated from the gained water and expressed as a percentage relative to the original weight of the sample.

\section{Color measurement}

The color of SP powders were measured using a model CR-10 colorimeter (Minolta, Japan) and the color values were recorded as Hunter $L, a$, and $b$ values.

\section{MP extraction}

Frozen pork sample $(200 \mathrm{~g})$ was thawed in a cold room overnight and minced before extracting the MP according to the method described by Xiong (1993) with slight modifications. The minced sample was mixed with 4 volumes of washing buffer $(100 \mathrm{mM} \mathrm{NaCl}, 50 \mathrm{mM}$ sodium phosphate, $\mathrm{pH}$ 6.25) and centrifuged at $1,000 \mathrm{~g}$ for 15 $\min$. The pellet was collected and washed twice with the washing buffer. The final pellet was re-suspended in 8 
volumes of $100 \mathrm{mM} \mathrm{NaCl}$ and filtered through two layers of gauze. The filtrate was collected for being centrifuged at $1,000 \mathrm{~g}$ for $15 \mathrm{~min}$. The obtained pellet was used as MP and the protein concentration was determined by the Biuret method (Gornall et al., 1949) using bovine serum albumin as a standard.

\section{MP and SP mixture preparation and characteriza- tion}

MP mixture was prepared at protein content of $4 \%$ in $0.45 \mathrm{M} \mathrm{NaCl}$ containing $50 \mathrm{mM}$ sodium phosphate, $\mathrm{pH}$ 6.25. Acid-treated fish SP (AFSP) was added to the protein content of $0.5 \%$. Those samples with or without MTG $(0.5 \%)$ were mixed and incubated at $4^{\circ} \mathrm{C}$ for $6 \mathrm{~h}$ before further characterization.

\section{Viscosity}

MP mixtures were diluted a half with $0.45 \mathrm{M} \mathrm{NaCl}$ containing $50 \mathrm{mM}$ sodium phosphate, $\mathrm{pH} 6.25$ prior to incubation at $4^{\circ} \mathrm{C}$ for $6 \mathrm{~h}$. The rheological properties were determined using a RC30 rotational rheometer (Rheotec Messtechnik GmbH, Germany) equipped with a bob $\left(120^{\circ}\right)$ and cup with radii of 7 and $7.59 \mathrm{~mm}$, respectively. The obtained shear stress values were recorded upon increasing shear rate.

Protein pattern of MP mixture (Sodium dodecyl sulfate polyacrylamide gel electrophoresis, SDSPAGE)

MP mixture after incubation with MTG for $6 \mathrm{~h}$ at $4^{\circ} \mathrm{C}$ was mixed with 10 times SDS solution (5\%) before it was boiled for $10 \mathrm{~min}$ in a water bath. The supernatant was collected by centrifugation at $1,000 \mathrm{~g}$ for $15 \mathrm{~min}$. The protein content in supernatant was analyzed by Biuret method (Gornall et al., 1949) and the pattern of protein in each sample $(20 \mathrm{mg})$ was analyzed by SDS-PAGE according to the method of Laemmli (1970) with slight modifications. The stacking and separating gels were 6.5 and $12.5 \%$, respectively. The samples were separated under constant voltage $120 \mathrm{~V}$ and protein bands were stained with Coomassie brilliant blue. The molecular weight of sample bands was estimated based on the broad range standard.

\section{MP gel preparation and characterization}

MP was controlled at $4 \%$ of protein in $0.45 \mathrm{M} \mathrm{NaCl}$ containing $50 \mathrm{mM}$ sodium phosphate, $\mathrm{pH}$ 6.25. Acidtreated fish SP (AFSP) was added (0.5\%). Those MP mixtures were prepared with or without MTG $(0.5 \%)$.
The mixtures were loaded into a glass vial $(\phi=12 \mathrm{~mm})$ for $5 \mathrm{~g}$ per each and incubated at $4^{\circ} \mathrm{C}$ for $6 \mathrm{~h}$. Each treatment was performed in five replications. All samples were heated from room temperature $\left(20^{\circ} \mathrm{C}\right)$ to $80^{\circ} \mathrm{C}$ using a waterbath (Daihan Scientific, Korea). The cooked samples were rapidly cooled in an ice mixed with water and maintained at $4^{\circ} \mathrm{C}$ overnight.

\section{Cooking loss $(\mathrm{CL})$}

The MP gels, stored in a cold room overnight, were brought to room temperature before measuring the exudates from MP gels. The amount of exudate in each treatment was used to calculate the CL and expressed as the percentage relative to the original weight of MP gel sample.

\section{Breaking force $(\mathrm{BF})$}

The $\mathrm{BF}$ values of MP gel were analyzed by a puncture test using the Instron Universal instrument (Instron, USA) equipped with a cylindrical probe $(\phi=9 \mathrm{~mm})$. The head speed was controlled at $50 \mathrm{~mm} / \mathrm{min}$ and the first peak was considered as the $\mathrm{BF}$ value.

\section{MP gel color}

The color of MP gels was evaluated using the colorimeter (CR-10, Minota, Japan) calibrated with the white plate standard. The color values were reported as the Hunter $L$, $a$, and $b$ values.

\section{Protein pattern of MP gel (SDS-PAGE)}

The MP gel was cut into small pieces before homogenizing with 10 volumes of SDS solution $(5 \%)$ and boiling for $10 \mathrm{~min}$. The supernatant was collected after centrifuged at $1,000 \mathrm{~g}$ for $15 \mathrm{~min}$ at room temperature. Protein concentration and pattern were analyzed according to the similar manner as described protocol for SDS-PAGE analysis of MP mixture.

\section{Microstructure}

The MP gels were analyzed for microstructure using scanning electron microscopy according to method described by Hemung and Chin (2013). The dried samples were gold-coated prior to examination with a JSM-7500F apparatus (JEOL, Japan).

\section{Statistical analysis}

The statistical difference of collected data was analyzed by ANOVA using PASW statistics 18 (SPSS, USA) and the $P \leq 0.05$ was considered as significant level. 


\section{Results and Discussion}

\section{Physicochemical characteristics of fish SP as affec- ted by acid or alkali treatment}

\section{Recovery yield}

Application of acid/alkaline treatments to fish SP solution resulted in protein precipitation, allowing SP to be easily recovered by centrifugation. This was due to the $\mathrm{pH}$ treatment, either acidic or alkaline conditions, induced changes in protein conformation (Gratacos-Cubarsi and Lametsch, 2008). However, recovery of SP by acid treatment was more effective than that by alkaline treatment. This was evidenced by high recovery yield when acidtreatment was applied (Table 1). Kim et al. (2005) noted that acid treatment was more effective than alkaline treatment to recover SP from rock fish. Kristinsson and Liang (2006) showed that the acid-aid process provided higher recovery yield than the alkaline process. In addition, an increased yield was due to SP recovery. Tadpitchayangkoon et al. (2010) reported that disulfide linkages and hydrophobic interactions among striped catfish SP were more profound at $\mathrm{pH} 3$ than at $\mathrm{pH} 12$. Such interactions induced protein aggregation and precipitation induced by disulfide linkages as well as hydrophobic interactions. These interactions were more induced by acid treatment rather than by alkaline treatment.

\section{WAC}

The WAC of AFSP powder was higher than that of alkaline-treated powder (Table 1). This WAC value was also higher than that of wheat protein isolates, non-fat dried milk, and dried egg white when the similar methods were used (Ahhmed et al., 2009). An improvement of the WAC of SP powder from threadfin bream by acid treatment was previously reported (Yongsawatdigul and He-

Table 1. Properties of fish SP powders obtained from acid and alkaline treatments

\begin{tabular}{ccc}
\hline \hline \multirow{2}{*}{ Characteristics } & \multicolumn{2}{c}{ Treatments } \\
\cline { 2 - 3 } & Acid-treated SP & Alkaline-treated SP \\
\hline Recovery yield (\%) & $18.64 \pm 1.11^{\mathrm{a}}$ & $4.56 \pm 0.64^{\mathrm{b}}$ \\
Water absorption & $2.72 \pm 0.08^{\mathrm{a}}$ & $2.32 \pm 0.07^{\mathrm{b}}$ \\
capacity (g/g sample) & & \\
\hline Color values & & \\
Hunter $L$ & $92.17 \pm 0.06^{\mathrm{a}}$ & $89.93 \pm 0.46^{\mathrm{b}}$ \\
Hunter $a$ & $2.40 \pm 0.00^{\mathrm{a}}$ & $1.63 \pm 0.06^{\mathrm{b}}$ \\
Hunter $b$ & $7.27 \pm 0.12^{\mathrm{a}}$ & $5.63 \pm 0.06^{\mathrm{b}}$ \\
\hline
\end{tabular}

Mean \pm SE was calculated based on 3 replicates.

${ }^{a, b}$ Different letters in the same row denote differences $(p \leq 0.05)$ between treatments. mung, 2010). Subjecting SP to acid treatment induced the formation of stable matrices that contain void spaces to absorb more water than that subjecting to the alkaline treatment.

\section{Color}

The color of AFSP powder was lighter than that of alkaline treatment (Table 1). Rawdkuen et al. (2009) reported that tilapia protein recovered by acid treatment became lighter than that did by alkaline treatment, although the total pigments as well as myoglobin content were higher. The denaturation of pigments was hypothesized to govern the whiteness of recovered protein. Therefore, the increased lightness that was more obvious by acid treatment than by alkaline treatment due to the greater degree of denaturation. According to our study, AFSP showed higher potential than alkaline counterpart in term of recovery yield and water absorption capacity. Therefore, it was selected for further studies the effects of AFSP on pork MP in the presence/absence of MTG.

\section{Rheological characteristics of MP mixture as affec- ted by AFSP and MTG}

\section{Viscosity}

Pork MP without MTG showed the maximum shear
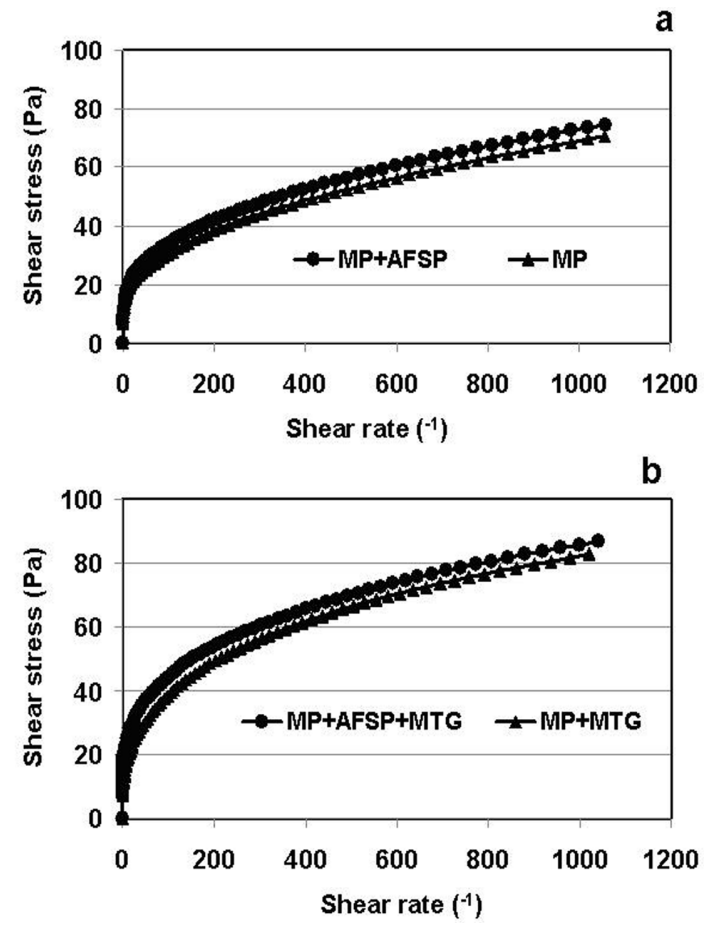

Fig. 1. Rheological properties of MP mixture in the presence/ absence of AFSP without (a) and with MTG (b). 
stress at about $80 \mathrm{~Pa}$ (Fig. 1a). An increase in this value to $90 \mathrm{~Pa}$ was observed when MTG was added (Fig. 1b). These results agreed with those reported previously (Hong and Chin, 2010). This suggested that MTG induces biopolymer formation, promoting protein-protein interactions. The shear stress of MP mixed with AFSP was slightly higher than MP alone, regardless of the presence of MTG, suggesting that an increased viscosity of the mixture was mainly due to the action of AFSP, which had high potential to hold water, as evidenced by high water absorption capacity (Table 1), facilitating protein hydration. Thus, molecular interactions between hydrated proteins were promoted, while the free water in the system was less available.

\section{Protein pattern of MP mixture}

Myosin heavy chain (MHC) band was observed at a molecular weight approximately $200 \mathrm{kDa}$ in the MP mixture without MTG. However, the MHC intensity was reduced in samples treated with MTG, concurrent with the formation of biopolymers at the top of staking gel (Fig. 2a). These results showed that the incubation of MP with MTG at this condition was sufficient for MTG to catalyze the MHC cross-linking. Carballo et al. (2006) reported that MHC was a favorite substrate for MTG, however, the cross-linking reaction of MHC could not be completed during incubation, as the remaining of MHC was observed. Protein patterns of sample with or without AFSP did not show any different (Fig. 2a, b). This suggested that the interactions between AFSP and MP did not affect the MTG activity toward MP. Increasing shear stress upon adding AFSP was partially due to only the physical adsorption of AFSP to water molecules.

\section{Physicochemical and rheological characteristics of MP gels with or without AFSP and MTG}

\section{Breaking force (BF) value}

MP gels with MTG showed about 3.5-fold higher BF than those without MTG (Table 2). The improvement of the textural properties of protein gel by MTG treatment has been widely documented (Ahmedna et al., 1999). The improvement of BF was partially due to the cross-linking of MHC induced by MTG. Addition of AFSP into MP gel did not affect the $\mathrm{BF}$ value of MP gels $(P>0.05)$. The gel weakening effect of fish MP gel was found when the SP powder (without any treatment) was added (Hemung and Chin, 2013). This suggests that modification fish SP by acid treatment prior incorporating into MP yield more
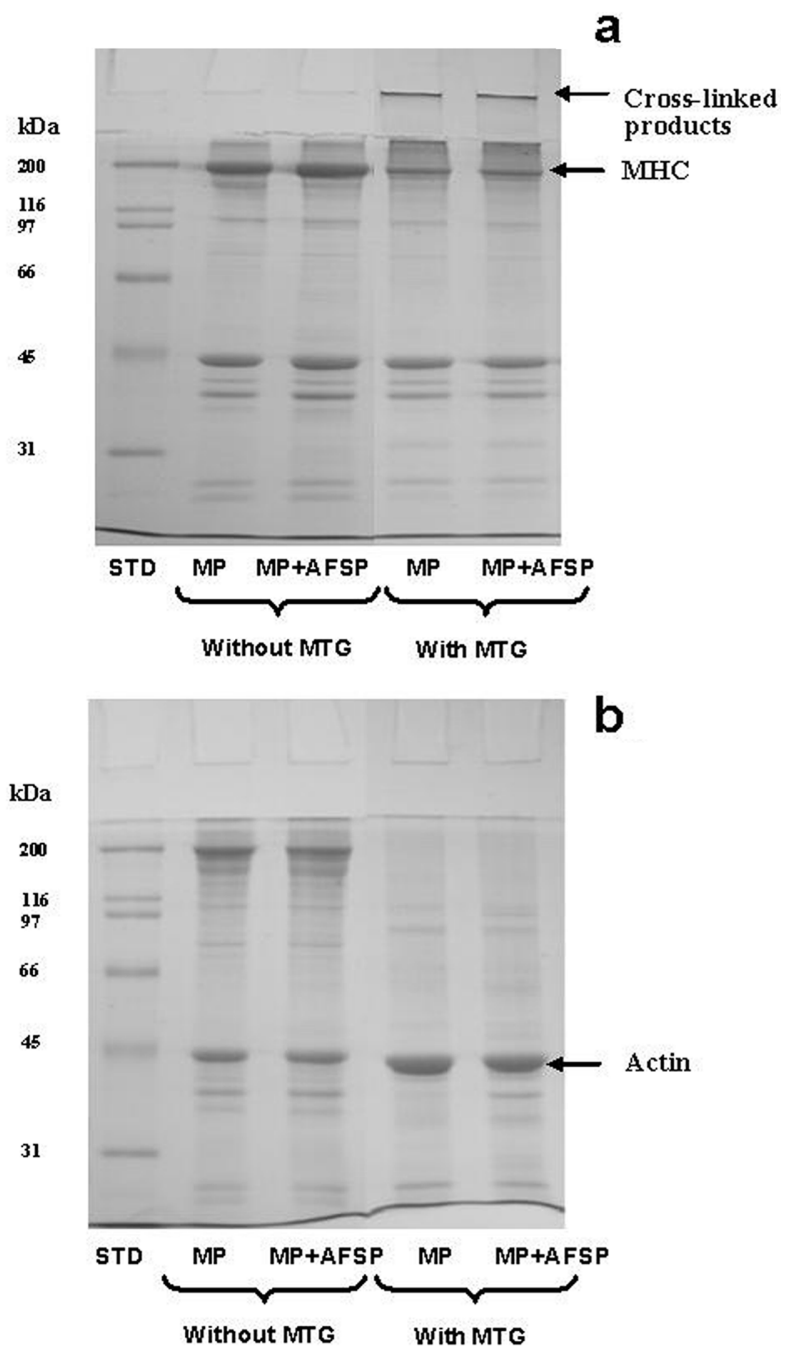

Fig. 2. SDS-PAGE patterns of MP incubated at $4^{\circ} \mathrm{C}$ for $6 \mathrm{~h}$ with/without MTG in the presence/absence of AFSP. Samples were taken before cooking (MP mixture) (a) and after cooking (MP gel) (b).

benefit by eliminating the inferior effect to the gelling properties. However, fish SP could improve the textural properties of protein gel and addition of carp SP to threadfin bream surimi increased gel strength (Jafarpour and Gorczyca, 2009). Rockfish SP improved the textural properties of its MP gel (Kim et al., 2005). Insoluble solids from surimi washed water increased the gel strength of Pacific whiting surimi (Ramirez et al., 2007). This suggests that effect of SP on gelation of protein is species specific.

In this study, treating fish SP under an acidic condition resulted in the formation of a stable matrix and those matrices may not be participated into the gelation of pork MP. In addition, the hydrated AFSP molecules could be neither a substrate for MTG nor interaction with MP. 
Table 2. Properties of MP gels with/without adding AFSP in the presence/absence of MTG

\begin{tabular}{cccc}
\hline \hline \multirow{2}{*}{ Properties } & MTG & \multicolumn{2}{c}{ Treatments } \\
\cline { 3 - 4 } & $(\%)$ & MP & MP+AFSP \\
\hline \multirow{2}{*}{ Breaking force (gf) } & 0 & $95.02 \pm 4.70^{\mathrm{Bab}}$ & $96.77 \pm 8.11^{\mathrm{Bb}}$ \\
& 0.5 & $354.99 \pm 35.55^{\mathrm{Aab}}$ & $333.98 \pm 24.75^{\mathrm{Ab}}$ \\
Cooking loss (\%) & 0 & $20.22 \pm 0.60^{\mathrm{Ba}}$ & $19.46 \pm 0.42^{\mathrm{Bb}}$ \\
& 0.5 & $35.63 \pm 0.87^{\mathrm{Aa}}$ & $33.13 \pm 0.23^{\mathrm{Ab}}$ \\
Hunter $L$ & 0 & $81.74 \pm 0.39^{\mathrm{Aa}}$ & $80.34 \pm 0.36^{\mathrm{Ab}}$ \\
& 0.5 & $77.58 \pm 0.44^{\mathrm{Ba}}$ & $76.88 \pm 0.51^{\mathrm{Bb}}$ \\
Hunter $a$ & 0 & $-0.82 \pm 0.22^{\mathrm{Aa}}$ & $-0.94 \pm 0.21^{\mathrm{Aa}}$ \\
& 0.5 & $-1.22 \pm 0.27^{\mathrm{Ba}}$ & $-2.08 \pm 0.29^{\mathrm{Bb}}$ \\
Hunter $b$ & 0 & $-6.66 \pm 0.25^{\mathrm{Ad}}$ & $-5.14 \pm 0.43^{\mathrm{Ac}}$ \\
& 0.5 & $-8.16 \pm 0.34^{\mathrm{Bc}}$ & $-6.18 \pm 0.11^{\mathrm{Ab}}$ \\
\hline
\end{tabular}

Mean \pm SE was calculated based on 5 replicates.

${ }^{\mathrm{A}, \mathrm{B}}$ Different letters in the same column denote differences ( $p \leq$ 0.05 ) between MTG levels.

${ }^{a, b}$ Different letters in the same row denote differences $(p \leq 0.05)$ among treatments.

Those molecules could be only the non-gelling filler interspersed into the gel matrix. The role of SPI as the non-gelling filler was also reported when the interactions between soy protein isolate and protein gel matrixes were not observed (Sun and Arntfield, 2012). This would explain that why the textural properties were not improved with the addition of AFSP. Although the improvement of MTG-mediated MP gel was not observed, the negative effect on textural properties did not occur, either. Based on this study, AFSP could be applied into the MTG-mediated protein gel, in which the texture is already improved.

\section{Cooking loss}

The CL of pork MP gel without MTG was not affected by AFSP addition $(P>0.05)$ and this value was lower than that with MTG by 1.75 -fold (Table 2). This result agreed with that for fish MP gel application (Hemung and Chin, 2013). The CL of pork meat gels increased upon addition of MTG (Pietrasik et al., 2007). Carballo et al. (2006) also reported that cooked batter with MTG showed higher CL than that without MTG. MP gel from pork also exhibited a lower cooking yield when the gels were incubated with MTG (Hong and Chin, 2010). These indicated that addition of MTG resulted in a drawback by increasing the cooking loss although it showed the powerful improvement on textural properties. High CL with MTG was generated because of the strong interaction between protein matrices by the isopeptide bond. Consequently, proteinprotein interactions were more favorable than proteinwater interactions. Thus, water molecules are excluded from the gel matrix, resulting in an exudation. It can be clearly seen that the CL of MTG-mediated MP gel was reduced by AFSP by $3.2 \%$ (Table 2). AFSP molecules absorbed water and became swollen, and then hydrated AFSP would act as the non-gelling filler embedded in the gel matrix, resulting in more retained water in gel structure. Therefore, AFSP could be a food ingredient to absorb water and reduce the cooking loss of protein gel in the presence of MTG.

\section{Color}

The color of MP gels was affected by MTG as a reduction in lightness ( $L$ value) (Table 2). Pietrasik (2003) reported that the color of comminuted meat products was changed by processing parameters including the addition or removal of water. The whiteness of gel prepared from Indian mackerel protein isolate was reduced upon a reduction of water (Chanarat and Benjakul, 2013). Since the color was measured after cooking loss, the amount of water in MTG-mediated gels would be less than that in gels without MTG. This was evidenced by high level of cooking loss of MP gels with MTG (Table 1). Therefore, the lower value of lightness in samples with MTG might be affected by the lower moisture content. The gel lightness was reduced in the presence of AFSP, regardless the addition of MTG. AFSP normally contains several pigments/enzymes and oxidation/denaturation of those proteins resulted in the browning reaction. Hunter $a$ value showed the negative value, representing the greenness rather than redness of sample. Addition of AFSP did not affect the Hunter $a$ value without MTG, but this value was reduced when MTG was incorporated. The blueness of the gel was recognized since the Hunter $b$ value was found to be negative number. However, the Hunter $b$ values were increased with AFSP addition $(P<0.05)$. These results suggested that the browning pigments in AFSP contributed to an increase the yellowness of MP gels, respectively. Our results were generally consistent with those reported by Kim et al. (2005) who noted that the addition of rockfish SP increased the $b$ value of surimi gel.

\section{Protein pattern of MP gel}

The protein patterns of MP gel without MTG were not changed, regardless of the presence of AFSP, and the actin band $(45 \mathrm{kDa})$ was distinctive in the gel (Fig. 2a). The cross-linked polymers at stacking gel were observed with the disappearance of MHC band by the addition of MTG. These results suggested that MHC molecules were used up to make a cross-linkage completely, however actin was not actively involved in the reaction of cross- 
linkage. However, undissolved polymers after cooking would likely precipitate out and could not show up in the SDS-PAGE pattern (Fig. 2b). This indicated that heating process activated MTG to catalyze the reaction more profoundly, resulting in completely using up the MHC. Since the protein patterns of MTG-mediated MP gels with/without AFSP were not different, interactions between AFSP and MP might affect neither the gelation process nor MTG action. This result was not agreed with that reported previously (Jiang and Xiong, 2013), who applied the acid-treated SPI to MTG-mediated MP gel. They found that subunit B of 11S interacted with MP and reinforced the gel mixture to improve texture. However, the native SPI did not exhibit the same behavior and interactions between native SPI and MP as well as textural improvement were not observed (Sun and Arntfield, 2012).

\section{Microstructure}

MTG-mediated MP gels exhibited a fibrous structure with a coarse gel matrix. In addition, the cross-linked strands and small voids were observed (Fig. 3a). This result suggested that soluble MP molecules unfolded and sometimes, aggregation to form the gel network up on heating. MTG also accelerate the aggregation by inducing the cross-linked protein via covalent bonding ( $\varepsilon-\gamma$ lysyl glutamine). Therefore, the small void in the gel matrix was observed. This result was in agreement with previous study by Benjakul et al. (2008), who reported that the surimi gel had small voids with added MTG. When AFSP was added into pork MP, the microstructure of MP gel was different from that without AFSP. Finer three-dimensional structures were observed, and the surface of the gel seemed to be more compact. Unlikely, hydrated AFSP particles were also observed (Fig. 3b). These hydrated particles would likely facilitate water retention and the hydrated particles of AFSP might be responsible for water retention.

\section{Conclusions}

SP from fish could be effectively recovered by acid treatment, and the recovered protein powder showed a good water absorption capacity. The incorporation of acid-treated fish SP into pork MP gel mediated by MTG resulted in a reduction of cooking loss without affecting the textural properties. Application of acid treatment to SP solution could be the effective strategy to recover the SP from waste water to be the water holding agent in MTG-mediated meat protein gel. a

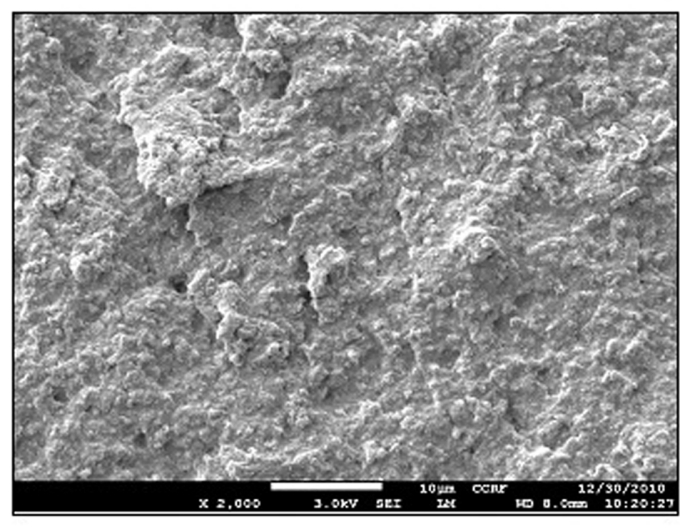

b

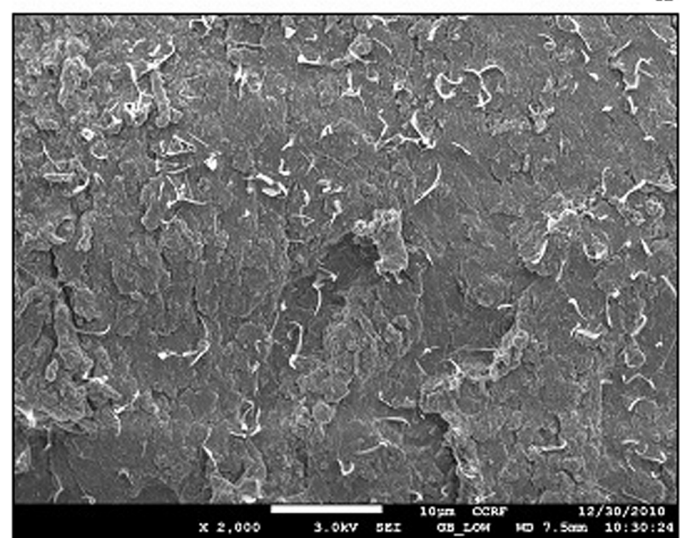

Fig. 3. Microstructure at $\times 2000$ magnification of MP gels treated with MTG in the absence (a) and presence of AFSP (b).

\section{Acknowledgements}

This work was carried out with the support of "Cooperative Research Program for Agriculture Science \& Technology Development (Project No. PJ009848)" Rural Development Administration, Republic of Korea.

\section{References}

1. Ahhmed, A. M., Kuroda, R., Kawahara, S., Ohta, K., Nakade, K., Aoki, T., and Muguruma, M. (2009) Dependence of microbial transglutaminase on meat type in myofibrillar proteins cross-linking. Food Chem. 112, 354-361.

2. Ahmedna, M., Prinyawiwatkul, W., and Rao, R. M. (1999) Solubilized wheat protein isolate: Functional properties and potential food applications. J. Agric. Food Chem. 47, 13401345.

3. Ando, H., Adachi, M., Umeda, K., Matsuura, M., Nonaka, M., Uchio, R., Tanaka, H., and Motoki, M. (1989) Purification and characteristics of novel transglutaminase derived from microorganisms. Agric. Biol. Chem. 53, 2613-2617. 
4. Benjakul, S., Phatcharat, S., Tammatinna, A., Visessanguan, W., and Kishimura, H. (2008) Improvement of gelling properties of lizardfish mince as influenced by microbial transglutaminase and fish freshness. J. Food Sci. 73, 239-246.

5. Carballo, J., Ayo, J., and Jimenez-Colmenero, F. (2006) Microbial transglutaminase and caseinate as cold binders: Influence of meat species and chilling storage. LWT-Food Sci. Technol. 39, 692-699.

6. Chanarat, S. and Benjakul, S. (2013) Impact of microbial transglutaminase on gelling properties of Indian mackerel fish protein isolates. Food Chem. 136, 929-937.

7. Gratacos-Cubarsi, M. and Lametsch, R. (2008) Determination of changes in protein conformation caused by $\mathrm{pH}$ and temperature. Meat Sci. 80, 545-549.

8. Go, W. and Hwang, M. S. (1995) Contribution of milkfish sarcoplasmic proteins to thermal gelation of myofibrillar protein. Fish Sci. 61, 75-78.

9. Gornall, A. G., Bardawill, C. J., and David, M. M. (1949) Determination of serum proteins by means of the biuret reaction. J. Biol. Chem. 177, 751-766.

10. Hemung, B. and Chin, K. B. (2013) Effects of fish sarcoplasmic proteins on the properties of myofibrillar protein gels mediated by microbial transglutaminase. LWT-Food Sci Technol. 53, 184-190.

11. Hong, G. P. and Chin, K. B. (2010) Effect of microbial transglutaminase and sodium alginate on cold set gelation of porcine myofibrillar protein with various salt levels. Food Hydrocolloid. 24, 444-451.

12. Jafarpour, A. and Gorczyca, E. M. (2009) Characteristics of sarcoplasmic proteins and their interactions with surimi and kamaboko gel. J. Food Sci. 74, 16-22.

13. Jiang, J. and Xiong, Y. L. (2013) Extreme pH treatments enhance the structure-reinforcement role of soy protein isolate and its emulsions in pork myofibrillar protein gels in the presence of microbial transglutaminase. Meat Sci. 93, 469476.

14. Kim, Y. S., Yongsawatdigul, J., Park, J. W., and Thawornchinsombut, S. (2005) Characteristics of sarcoplasmic proteins and their interaction with myofibrillar proteins. J. Food Biochem. 29, 517-531.

15. Kristinsson, H. G. and Liang, T. (2006) Effect of pH-shift processing and surimi processing on Atlantic croaker (Micropogonias undulates) muscle proteins. J. Food Sci. 7, 298-306.

16. Laemmli, U. K. (1970) Cleavage of structural proteins during the assembly of the head of bacteriophage T4. Nature. 227, 680-685.
17. Lin, T. M., Park, J. W., and Morrissey, M. T. (1995) Recovered proteins and reconditioned water from surimi processing waste. J. Food Sci. 50, 4-9.

18. Montero, P. and Gomez-Guillen, M. C. (1998) Recovery and functionality of wash water protein from krill processing. $J$. Agric. Food Chem. 46, 3300-3304.

19. Perez-Alvarez, J. A., Sayas-Barbera. M. E., Fernandez-Lopez, J., and Aranda-Catala, V. (1999) Physicochemical characteristics of Spanish-type dry-cured sausage. Food Res. Inter. 32, 599-607.

20. Pietrasik, Z., Jarmoluk, A., and Shand, P. J. (2007) Effect of non meat proteins on hydration and textural properties of pork meat gels enhanced with microbial transglutaminase. LWT-Food Sci. Technol. 40, 915-920.

21. Pietrasik, Z. (2003) Binding and textural properties of beef gels processed with k-carrageenan, egg albumin and microbial transglutaminase. Meat Sci. 63, 317-324.

22. Ramirez, J. A., Angel, A. D., Uresti, M., Velazquez, G., and Vazquez, M. (2007) Low salt restructured products from striped mullet (Mugil cephalus) using microbial transglutaminase or whey protein concentrates as additives. Food Chem. 102, 243-249.

23. Rawdkuen, S., Sai-Ut, S., Khamsorn, S., Chaijan, M., and Benjakul, S. (2006) Biochemical and gelling properties of tilapia surimi and protein recovered using an acid-alkaline process. Food Chem. 112, 112-119.

24. Sun, X. D. and Arntfield, S. D. (2012) Gelation properties of myofibrillar/pea protein mixtures induced by transglutaminase crosslinking. Food Hydrocolloid. 27, 394-400.

25. Tadpitchayangkoon, P., Park, J. W., Mayer, S. G., and Yongsawatdigul, J. (2010) Structural Changes and dynamic rheological properties of sarcoplasmic proteins subjected to $\mathrm{pH}-$ shift method. J. Agric. Food Chem. 58, 4241-4249.

26. Tadpitchayangkoon, P., Park, J. W., and Yongsawatdigul, J. (2010) Conformational changes and dynamic rheological properties of fish sarcoplasmic proteins treated at various $\mathrm{pHs}$. Food Chem. 121, 1046-1052.

27. Yongsawatdigul, J. and Hemung, B. (2010) Structural changes and functional properties of threadfin bream sarcoplasmic proteins subjected to $\mathrm{pH}$-shifting treatments and lyophilization. J. Food Sci. 75, 251-257.

28. Xiong, Y. L. (1993) A comparision of the rheological characteristics of different fractions of chicken myofibrillar proteins. J. Food Biochem. 16, 217-227.

(Received 2014.8.22/Revised 2014.11.10/Accepted 2014.11.19) 